\title{
Psychiatric evaluation of intellectually disabled offenders referred to the Free State Psychiatric Complex, 1993 - 2003
}

F J W Calitz, BA Hons, MA (Clin Psychol)

P H J J van Rensburg, MB ChB, MMed (Psych), PhD

$P$ P de Jager, $M B C h B$

$M L$ Olander, $M B C h B$

L Thomas, MB ChB

R Venter, $M B C h B$

G A Wessels, MB ChB

Department of Psychiatry, University of the Free State, Bloemfontein

\section{G Joubert, BA MSC}

Department of Biostatistics, University of the Free State, Bloemfontein

Background. Increased crime is a problem in South Africa and complications arise when the accused is intellectually disabled. The accountability and fitness to stand trial of such individuals is an important facet that needs to be managed by the judicial and health systems.

Objective. To analyse the accountability and triability of intellectually disabled people awaiting trial referred to the Free State Psychiatric Complex (FSPC) from 1993 to 2003 according to Sections 77 and 78 of the Criminal Procedures Act (Act 51 of 1977).

Method. A retrospective study was conducted. The study population consisted of 80 intellectually disabled people awaiting trial in the Free State, referred to the FSPC. The reason for referral was the possibility that they were not triable or accountable. A data form was compiled to transfer the relevant information from the patients' clinical files.

Results. The study found that the majority of subjects were male $(96.3 \%)$, unmarried $(76.3 \%)$ and unemployed $(63.8 \%)$. The median age was 27 years. A relatively high percentage $(49 \%)$ had received some schooling and $16 \%$ had attended a special school. Most $(32 \%)$ were referred from the Bloemfontein area and $68 \%$ were referred from the remainder of the Free State and other areas. The majority were referred according to Sections 77 and 78. The highest number of the offences were of a sexual nature (78\%). Of the subjects, $62(62.5 \%)$ were diagnosed as having mild mental retardation, while 16\% were diagnosed as having moderate mental retardation. A total of $71(71.25 \%)$ were found to be untriable and unaccountable.

Conclusion. Triability and accountability are not only reflected by IQ score, but also involve the accused's understanding of his/her environment, his/her speech and language proficiency, level of education, reasoning ability and the manner in which the crime was committed. It is important to note that having an $I Q$ of 70 or less does not automatically mean that the accused is unfit to stand trial or is not accountable. It is possible for an intellectually disabled person to be triable, accountable or diminished accountable.

'Not too long ago the belief prevailed that insanity was a divine punishment for more or less identifiable sin. Such a belief clearly did not justify exemption from punishment for crimes committed by mentally ill persons. "Increase in crime is a problem of great concern in South Africa and complications arise when the accused is intellectually disabled. The accountability and triability of such individuals is an important facet that needs to be managed by the judicial and health systems.

In South Africa a defendant can be referred during a trial in terms of Section 79(2) of the Criminal Procedures Act for 30 days of psychiatric observation to assess whether he/she has a mental illness or defect. If mental illness is diagnosed, the accused is considered unable to stand trial (Section 77) and/ or is considered 'incapable of appreciating the wrongfulness of his act; or of acting in accordance with the appreciation of the wrongfulness of his act' (Section 78). ${ }^{2}$ When it appears that an accused is not triable or accountable, he/she is referred for psychiatric observation to a hospital for the mentally ill or to another institution as indicated by the court (Section 79(3)). . $^{3-5}$

The Diagnostic and Statistical Manual of Mental Disorders $(D S M-I M)^{6}$ defines mental retardation as sub-average intellectual functioning (IQ of 70 or less) combined with 
limitations in skill areas related to mental functioning. Onset of the disability must occur before the age of 18 years. ${ }^{7,8}$ According to the Amendment of Section 77 of Act 51 of 1977, the term 'intellectually disabled' is the legal term used to refer to persons considered 'mentally disabled' ${ }^{\prime 9}$ or mentally retarded, and it is the term used in this study.

Various studies have been conducted in South Africa. A local study by Verster and Van Rensburg ${ }^{10}$ examined the mental state of offenders admitted to the Free State Psychiatric Complex (FSPC) for psychiatric observation after committing homicide (1989 - 1998). Five of 126 perpetrators (3.9\%) were found to be intellectually disabled. Of these, 2 were diagnosed apsychotic and not criminally responsible, while the remaining 3 were diagnosed as psychotic.

These findings correlate with those of Pretorius et al., "1 who conducted a retrospective study entitled 'Marijuana use among law offenders referred by a court of law for 30 days of psychiatric observation'. The study sample consisted of 283 individuals referred from 1991 to 1993. Of these, $19(6.7 \%)$ were found to be intellectually disabled, with 2 moderately disabled, 3 borderline and 14 mildly disabled.

Some psychiatrists and psychologists are of the opinion that if an individual's $I Q$ is 70 or less, he/she is automatically untriable and/or unaccountable. As a result these individuals are then declared state patients. However these persons are sometimes totally capable of defending themselves on minor charges.

Triability and accountability are therefore not only reflected by $I Q$, but also involve the accused's understanding of his/her environment, his/her speech and language proficiency, level of education, reasoning ability and the manner in which the crime was committed. ${ }^{12-14}$ In his 'Checklist for psychiatrists' Robey $^{15}$ is of the opinion that a person with an $I Q$ of 60 can sometimes be triable. The American Bar Association has termed 'competence to stand trial the most important issue in the field of mental disability criminal law today'. ${ }^{5}$

The authors support the Mental Health American Standards and Guidelines for Affiliates, namely that 'If a defendant is capable of meeting the articulated requirements for competency to stand trial, the presence or absence of mental illness is irrelevant. The same is true for mental retardation. ${ }^{13}$

From the above it is clear that complications arise when the accused is intellectually disabled. It also appears that an accused who is intellectually disabled is not necessarily considered untriable and/or unaccountable. Care must therefore be taken with regard to psychiatric evaluation and court procedures involving the intellectually disabled.

\section{Objective}

The aim of the study was to analyse the triability and accountability of intellectually disabled offenders referred to the FSPC from 1993 to 2002 in terms of Sections 77 and/or 78 of the Criminal Procedures Act (Act 51 of 1977).

\section{Methods}

\section{Study design}

A descriptive, retrospective study was undertaken

\section{Study population}

The study group consisted of 80 intellectually disabled persons awaiting trial in the Free State, referred to the FSPC for 30 days' observation in terms of Sections 77 and/or 78 of the Criminal Procedures Act, from 1993 to 2003. The total number of people awaiting trial was 1203 , of which $80(6.7 \%)$ were diagnosed as intellectually disabled. The reason for their referral was the possibility that they were not triable or accountable.

The multi-professional team at the forensic unit of the FSPC included a psychiatrist, psychiatry registrar, social worker, clinical psychologist, psychiatric professional nurse, occupational therapist, neurologist and juror.

During the 30 days' observation the subjects underwent several physical and mental assessments. Evaluations included psychiatric interviews, psychological tests, physical examination, a psychosocial report and evaluation of the facts of the case.

On admission each person was examined physically. Thereafter the accused was evaluated at least once a week by means of a structured psychiatric interview. The interview centred on the clinical picture, psychosocial background, the individual's account of the crime and ability to understand court proceedings. When needed, translators were used. Comprehensive notes were taken. Before the final report was written by the psychiatrist, a battery of physical tests were also done. All the abovementioned information was filed in the accused's clinical file. 
At the end of the 30-day observation period and after all the data had been collected, the multi-professional team held a forensic conference to discuss the information in detail. A diagnosis was formulated and a finding was reached regarding the triability and/or accountability of the accused. Thereafter the report was compiled for the court

\section{Measurement}

A data form was compiled and used to transfer the relevant information from the accused's clinical file.

\section{Data analysis}

The data were analysed by the Department of Biostatistics at the University of the Free State.

\section{Results and discussion}

\section{Biographical information}

There were 77 male and 3 female intellectually disabled offenders. The majority were unmarried.

The study population ranged in age from 14 to 48 years, with the majority aged between 16 and 36 years (Fig. 1). The median age was 27 years, while the mode was 25 years and the mean 27 years and 10 months.

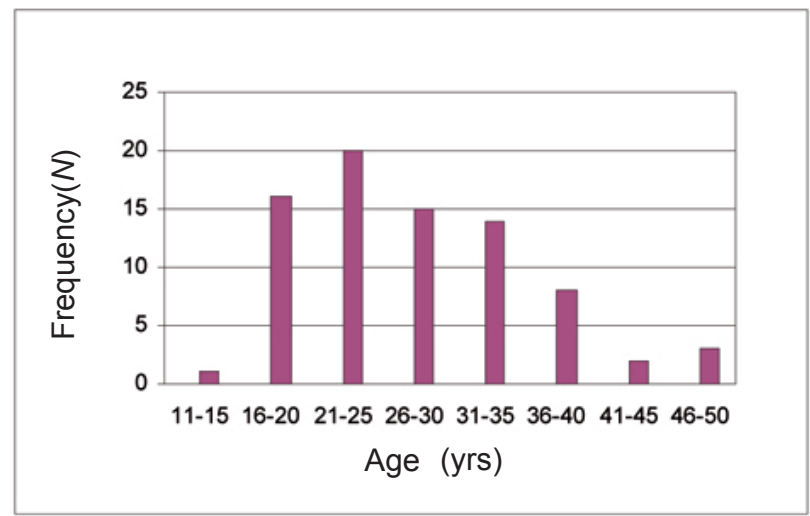

Fig. 1. Age distribution.

The majority (62.5\%) of the subjects were diagnosed with mild mental retardation (Fig. 2). A total of $20 \%$ of the mild mentally retarded offenders were also diagnosed with epilepsy. There was a far smaller number of persons in the moderate retardation category, and there were no offenders in the profound mental retardation category. This may correlate with their decreased ability to commit a crime. Of the records, $12.5 \%$ did not indicate the severity of intellectual disability.

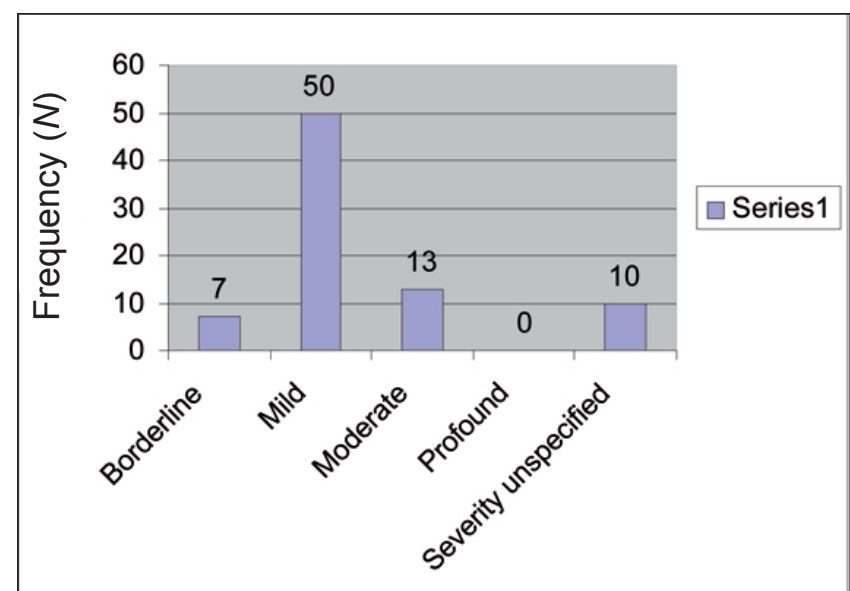

Fig. 2. Level of intellectual functioning.

Although all the persons included in the study were diagnosed as intellectually disabled, 7 were regarded as borderline but were included in the study.

Of the offenders, 26\% had never attended school (Table I). This may have been due to the fact that they did not have access to the necessary special schooling, or they may simply not have attended school.

While 39 (49\%) had obtained some form of mainstream schooling, less than one-quarter ( 8 of the 39) had obtained grade 8 or higher. Sixteen per cent had attended special schools and $9 \%$ of the records did not indicate whether the persons had attended school.

A 63.8\% unemployment rate was found (Table II). Unemployment may have been a motivational factor for the persons to commit crime. None of the occupations recorded required a secondary qualification. This correlates with the fact that none of the subjects had completed their schooling, although some had attended special schools where they learnt skills such as carpentry or welding.

\section{Demographic information}

The Free State is divided into five districts, namely Motheo (District Council (DC) 17), Xhariep (DC 16), Lejweleputswa (DC 18), Northern Free State (DC 20) and Thabo

\section{Table I. Type of education}

\begin{tabular}{ll}
\hline Education & Number of persons (\%) \\
\hline No schooling & $21(26)$ \\
Schooling & $39(49)$ \\
Special school & $13(16)$ \\
Unknown & $7(9)$ \\
\hline
\end{tabular}




\begin{tabular}{ll} 
Table II. Occupation of the offenders \\
\hline Occupation & Number of individuals \\
\hline Unemployed & 51 \\
Scholar & 5 \\
Farm worker & 4 \\
Security guard & 3 \\
Carpenter & 2 \\
Farmer & 2 \\
Other occupation & 11 \\
Unknown & 2 \\
Total & 80 \\
\hline
\end{tabular}

Mofutsanyane (DC 19). This division was used in analysis of the data. The demographic information is given in Fig. 3.

Most persons (32\%) were from the Bloemfontein (DC 17) area as it has a relatively large population and the FSPC is easily accessible. In the Bloemfontein area there are more advanced judicial systems (police infrastructure, legal advice and courts) resulting in a greater number of individuals being apprehended and later referred.

\section{Referrals according to Sections 77 and/or 78}

The data in Fig. 4 show the referrals to the FSPC in terms of Sections 77 and/or 78 .

The majority (85\%) of the subjects were referred according to Sections 77 and 78

\section{Alleged offences committed by the offenders}

The findings concerning the alleged offences are presented in Tables III and IV.

The most common offences against persons were rape, murder and indecent assault. Of the offences against persons, $78 \%$ were of a sexual nature, and the number of persons who committed this type of offence constituted $53.8 \%$ of the total study population. The remainder of the offences against

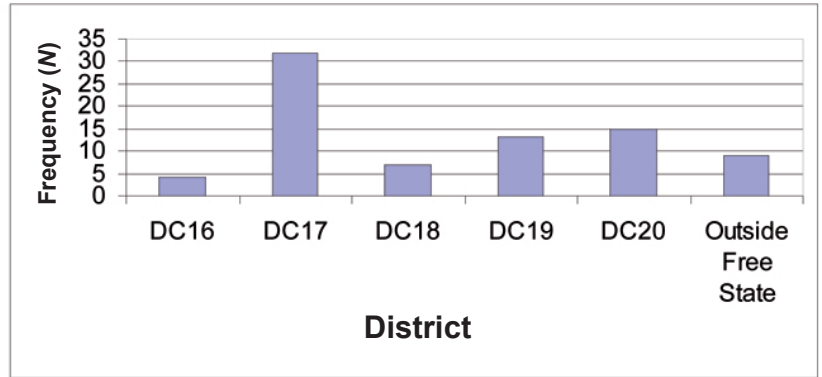

Fig. 3. District where the offence was committed.

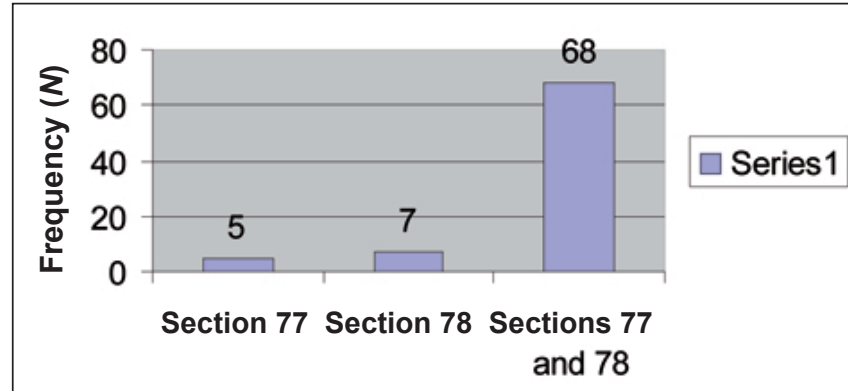

Fig. 4. Referrals in terms of Sections 77 and/or 78.

\begin{tabular}{lc}
\multicolumn{2}{l}{ Table III. Alleged offences against persons } \\
\hline Alleged offences & No. of individuals \\
against persons & 27 \\
\hline Rape & 10 \\
Murder & 10 \\
Indecent assault & 4 \\
Sodomy & 2 \\
Attempted rape & 2 \\
Child molestation & 1 \\
Sexual molestation & 1 \\
Attempted murder & 1 \\
Death intimidation & 1 \\
Intimidation & 59 \\
Total & \\
\hline
\end{tabular}

\begin{tabular}{|c|c|}
\hline $\begin{array}{l}\text { Offences against } \\
\text { property }\end{array}$ & No. of individuals \\
\hline Theft & 19 \\
\hline Housebreaking & 7 \\
\hline Arson & 2 \\
\hline Public violence & 1 \\
\hline Malicious damage & 1 \\
\hline
\end{tabular}

persons were of a violent nature. Some individuals committed more than one offence. The majority of offences against property involved theft and housebreaking (see Table IV).

\section{Findings on triability and accountability}

Fig. 5 presents the findings on triability and accountability.

The majority of the offenders (71.25\%) were found to be untriable and unaccountable and $28.75 \%$ were found to be triable and accountable. This finding supports the view of Robey, ${ }^{15}$ viz. that offenders with an IQ of 60 'can sometimes be triable and/or accountable'. 


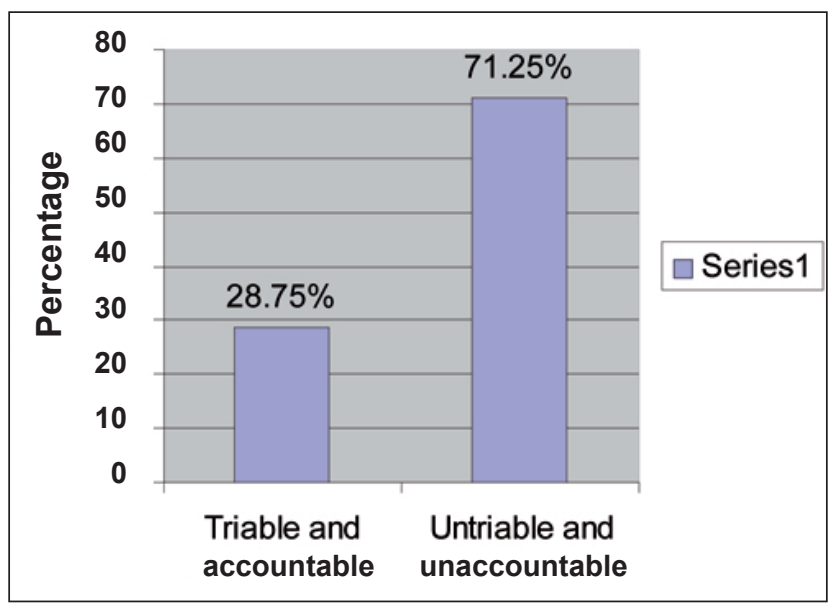

Fig. 5. Findings on triability and/or accountability.

\section{Conclusion and recommendations}

The study showed that the majority of the intellectually disabled accused were male (96.3\%), unmarried (76.3\%) and unemployed $(63.8 \%)$. The median age of the study group was 27 years. Of the subjects, $49 \%$ had received some schooling and $32 \%$ had attended a special school. Of the offenders referred, $40 \%$ were referred from the Bloemfontein area and $68 \%$ from the remainder of the Free State and other areas. The majority were referred in terms of Sections 77 and 78.

Most of the offences were committed against persons. Of the intellectually disabled, $62.5 \%$ were diagnosed as having mild mental retardation and $16 \%$ as having moderate mental retardation. Of the accused, $71.25 \%$ were found to be untriable and unaccountable.

The study had several limitations. A few of the patient files were unavailable, which affected the absolute accuracy of the study data. Complications arose with regard to obtaining complete demographic information for some subjects, and discrepancies arose between the information obtained from the persons themselves and that obtained from the family. One of the intellectually disabled persons was readmitted for observation on a second offence, and 7 were diagnosed as having borderline intellectual functioning.

The study showed that a significant number of serious crimes are committed by the intellectually disabled; this is a problem in the Free State and probably in the rest of South Africa. This problem can be addressed by implementing the following steps.
1. The community should be educated in terms of caring, accepting, guiding and not abusing intellectually disabled individuals. This education should focus especially on family members. It is important to emphasise acceptance of the individual in the community by providing such individuals with a role in the community like sheltered employment and step-down facilities.

2. Community infrastructure, for example churches, societies, schools and organisations, should support existing social structures for the intellectually disabled, ensuring that the latter are not left unattended and therefore exposed to the possibility of committing a crime.

3. Psychologists and social workers should be trained in providing counselling and support to intellectually disabled individuals and their families, enabling them to function as a family unit and cope with the psychological and social implications of intellectual retardation.

4. Facilities are needed where the individual can be trained and provided with work (for example farms and workshops) as this provides the individual with a sense of self-worth and enables him/her to generate a small income. These facilities provide the opportunity for social interaction, enabling the individual to obtain muchneeded social support.

5. Within each district step-down facilities should be provided as a safe haven where the individual can receive individualised care as necessary, as well as rehabilitation and training.

6. If an individual is found to be triable and accountable, he/she should be sent to a facility that offers the required environment. These individuals should preferably not be sent to institutions such as prisons or assessment centres as they are vulnerable to abuse and influence.

Lastly, it is important to note that an IQ of 70 or less does not automatically mean that the accused is not fit to stand trial or is not accountable. For instance it may be possible that the accused is fit to stand trial or is accountable or diminished accountable. The facts of the alleged crime are also very important in coming to a decision.

\section{References}

1. Silving H. Essays on Mental Incapacity and Criminal Conduct. Florida, III.: Charles C Thomas, 1967 
2. Kaliski SZ, Borcherds M, Williams F. Defendants are clueless - the 30 day psychiatric observation. S Afr Med J 1997; 87: 1351-1354

3. Juta Wetgewersdiens. Strafproseswet, Wet 51 van 1977. Kaapstad: Juta, 1985.

4. Hiemstra VG. Suid-Afrikaanse Strafproses. 5th ed. Durban: Butterworth, 1993.

5. Everington $C T$. The competence assessment for standing trial for defendants with mental retardation (CAST-MR) - a validation study. Criminal Justice and Behaviour 1990; 17: 147-168

6. American Psychiatric Association. Diagnostic and Statistical Manual of Mental Disorders. 4th ed. Washington, DC: APA, 1994.

7. Robertson B, Allwood CW, Gagiano CA. Textbook of Psychiatry for Southern Africa. Cape Town: Oxford University Press, 2001.

8. Allwood CW, Gagiano CA. Handbook of Psychiatry for Primary Care. Cape Town Oxford University Press, 1997.

9. Amendment of Section 77 of Act 51 of 1977. South African Government Gazette, 17 January 2003.
10. Verster I, Van Rensburg PHJ. Mental disorders in patients referred for psychiatric observation after committing homicide. Journal of Juridical Science 1999; 24(1): 58-66.

11. Pretorius PJ, Van Rensburg PHJ, Gagiano CA, Oostuizen H. Daggagebruik deu wetsoortreders wat deur die hof vir 30 dae psigiatriese observasie verwys word. Geneeskunde 1996; 38(2): 43-50.

12. Faulk M. Basic Forensic Psychiatry. London: Blackwell Scientific Publications, 1988.

13. Ellis JW, Luckasson RA. Mentally retarded criminal defendants. George Washington Law Review 1985; 53(3/4): 4 14-493.

14. Verschoor T, Van Rensburg PHJJ. Kriteria vir verhoorbaarheid. Suid-Afrikaanse Tydskrif vir Strafreg en Kriminologie 1983; 7(1): 16-19.

15. Robey A. Criteria for competency to stand trial: A checklist for psychiatrists. Am J Psychiatry 1965; 122(6): 616-622. 